\title{
Internalizing symptomatology and academic achievement: bi-directional prospective relations in adolescence \\ Article
}

Accepted Version

Weidman, A. C., Augustine, A. A., Murayama, K. and Elliot, A. J. (2015) Internalizing symptomatology and academic achievement: bi-directional prospective relations in adolescence. Journal of Research in Personality, 58. pp. 106114. doi: https://doi.org/10.1016/j.jrp.2015.07.005 Available at https://centaur.reading.ac.uk/58429/

It is advisable to refer to the publisher's version if you intend to cite from the work. See Guidance on citing.

To link to this article DOI: http://dx.doi.org/10.1016/j.jrp.2015.07.005

All outputs in CentAUR are protected by Intellectual Property Rights law, including copyright law. Copyright and IPR is retained by the creators or other copyright holders. Terms and conditions for use of this material are defined in the End User Agreement.

www.reading.ac.uk/centaur 
Central Archive at the University of Reading

Reading's research outputs online 
In Press, Journal of Research in Personality

Running Head: INTERNALIZING SYMPTOMATOLOGY AND ACADEMIC ACHIEVEMENT

Internalizing Symptomatology and Academic Achievement:

Bi-Directional Prospective Relations in Adolescence

\author{
Aaron C. Weidman ${ }^{1}$ \\ Adam A Augustine ${ }^{2}$ \\ Kou Murayama $^{34}$ \\ Andrew J. Elliot ${ }^{5}$
}

${ }^{1}$ University of British Columbia

${ }^{2}$ Beta Zero Research Solutions

${ }^{3}$ University of Reading

${ }^{4}$ Kochi University of Technology

${ }^{5}$ University of Rochester

Correspondence concerning this article should be addressed to Aaron C. Weidman, University of British Columbia, Department of Psychology, 2136 West Mall, Vancouver, BC, V6T 1Z4, Canada (email: acweidman@psych.ubc.ca; phone: 604-822-3995; fax: 604-822-6923).

\title{
Acknowledgements
}

This research was supported in part by a William T. Grant Foundation grant (2585) to Andrew J. Elliot. Thanks are extended to the administrators at the Rush-Henrietta Central School District for their assistance, and gratitude is expressed to the parent and student participants in the project. This research was also partly supported by the Marie Curie Career Integration Grant (CIG630680; to Kou Murayama) and JSPS KAKENHI (Grant Number 15H05401; to Kou Murayama). 


\begin{abstract}
Prior research has documented negative, concurrent relations between internalizing symptomatology and academic achievement among adolescents. The present study provided the first rigorous, longitudinal examination of the bi-directional, prospective relations between adolescent internalizing symptomatology and academic achievement. One hundred and thirty adolescents reported depression and anxiety annually from $6^{\text {th }}$ through $10^{\text {th }}$ grades, and GPA records were obtained annually from schools. Results showed that a) high depression and anxiety at the beginning of a school year predicted lower GPA during that school year, and b) low GPA in any school year predicted higher depression and anxiety at the beginning of the following school year. These findings underscore the tight link between adolescent internalizing symptomatology and academic achievement.
\end{abstract}

Keywords: academic achievement, depression, anxiety, adolescence, longitudinal 


\section{Internalizing Symptomatology and Academic Achievement: \\ Bi-Directional Prospective Relations in Adolescence}

A substantial body of research suggests that internalizing symptomatology is negatively linked with concurrent academic performance in adolescent samples that cut across gender, age, socioeconomic status, ethnicity, and nationality (for reviews, see Hishinuma, Chang, McArdle, \& Hamagami, 2012; Seipp, 1991). ${ }^{1}$ To date, however, no rigorous longitudinal studies have examined this link, leaving the temporal dynamics underlying these relations underexplored. This gap in the literature is problematic, given that elevated internalizing symptomatology and poor academic performance often shape the adolescent experience. Estimates from the National Comorbidity Survey Replication-Adolescent Supplement suggest that approximately 12 percent of adolescents had experienced an episode of major depression or dysthymia and over 30 percent had been diagnosed with an anxiety disorder (Merikangas et al., 2010); furthermore, estimates for sub-clinical levels of depression and anxiety run as high as 20-40 percent, particularly in certain at-risk subgroups (e.g., females, ethnic minorities; Saluja et al., 2004). Additionally, the National Center for Education Statistics in the U.S. estimates that approximately $25 \%$ of junior high students have minimal or no mastery of fundamental skills in reading and mathematics, and nearly 10 percent of young adults aged 16-24 are not enrolled in school and have not earned a high school degree (Aud et al., 2012).

In the present research, we therefore conducted the first rigorous, longitudinal study of the relation between internalizing symptomatology and academic achievement in adolescence. We sought to answer two questions: a) Does poor academic achievement predict subsequent increases in internalizing symptomatology?, and b) Does elevated internalizing symptomatology predict subsequent declines in academic performance? To answer these questions, we followed a 
group of adolescents from $6^{\text {th }}$ through $10^{\text {th }}$ grades, obtaining annual assessments of self-reported depression and anxiety at the beginning of each school year and school records of GPA at the end of each school year.

\section{Does Poor Academic Achievement Predict Subsequent Increases in Internalizing}

\section{Symptomatology?}

Stressful life events are commonly thought to precipitate the onset of internalizing symptomatology (Brown \& Harris, 1978; Hammen, 2005; Hudson \& Rapee, 2004; Monroe \& Reid, 2009). Individuals who experience internalizing symptomatology report having experienced stressful life events over the prior 6-12 months at a higher rate than healthy individuals (e.g., Allen, Rapee, \& Sandberg, 2008; Brown, Bifulco, Harris, \& Bridge, 1986; Kendler, Karkowski, \& Prescott, 1999), and this effect has been repeatedly demonstrated among adolescents (e.g., Cole, Nolen-Hoeksema, Girgus, \& Paul, 2006; Hankin, Mermelstein, Roesch, 2007; Rudolph, Flynn, Abaied, Groot, \& Thompson, 2009). Importantly, Kendler and colleagues (1999) employed a large sample of twins to demonstrate that stressful life events play a causal role in precipitating internalizing symptomatology, above and beyond underlying genetic factors that could cause individuals to experience both stress and internalizing symptomatology. However, although interpersonal events (e.g., those involving loss, or rejection from a close friend) have typically been implicated as the most potent at inducing internalizing symptomatology in both adults (Brown, Bifulco, \& Harris, 1987; Kendler, Hettema, Butera, Gardner, \& Prescott, 2003) and adolescents (Hankin et al., 2007: Harkness, Alavi, Monroe, Slavich, Gotlib, \& Bagby, 2010), little work has examined achievement-related stressors. Evidence suggests that achievement related stress may also precipitate internalizing symptomatology among adolescents. For example, poor academic performance over time has 
numerous inimical effects, including low perceptions of competence and self-efficacy (Bandura, 1986; Wigfield, Eccles, MacIver, Reuman, \& Midgley, 1991) and feelings of hopelessness, distress, and low self-esteem (Blyth, Simmons, \& Carlton-Ford, 1983; Harter, Whitesell, \& Kowalski, 1992; Moilanen, Shaw, \& Maxwell, 2010), all of which may lead to the onset of depression or anxiety (e.g., Bandura, Pastorelli, Barbaranelli, \& Caprara, 1999; Hankin, Abramson, \& Siler, 2001; Sowislo \& Orth, 2013). Repeated academic failure can also lead students to adopt performance-impairing behaviors in an effort to protect their damaged selfimages, including reduced task engagement, avoidance of optimal challenge, and divestment from academic pursuits (Elliot \& Church, 2003; Osborne, 1997). Given this evidence, it seems reasonable to posit academic achievement as a negative prospective predictor of internalizing symptomatology.

\section{Does Elevated Internalizing Symptomatology Predict Subsequent Declines in Academic}

\section{Performance?}

Internalizing symptomatology is associated with numerous motivational, cognitive, and biological processes that are likely to disrupt learning and performance. From a motivational standpoint, depressive symptoms are negatively related to approach-based goal pursuit and striving for rewards (Dickson \& MacLeod, 2004; Shankman, Klein, Tenke, \& Bruder, 2007; Strauman, 2002), and anxiety symptoms are positively related to avoidance-based goal pursuit and vigilance for threats (Derryberry \& Reed, 2002; Dickson \& MacLeod, 2004; Higgins, Shah, \& Friedman, 1997); both diminished approach and heightened avoidance motivation can impair academic achievement (Elliot \& Church, 1997; Oertig et al., 2012). Cognitively, depression promotes a memorial bias for negative events, facilitates rumination, reduces working memory capacity, and impairs one's ability to inhibit distracting information (Gotlib \& Joorman, 2010; 
Nolen-Hoeksema, Wisco, \& Lyubomirsky, 2008), and anxiety facilitates a narrow, inflexible focus on negative possibilities that can distract students from academic work and make learning and integrating information difficult (Eysenck, Derakshan, Santos, \& Calvo, 2007); these cognitive tendencies are likely to impair students' ability to learn new information and perform on demanding school assignments and exams. From a biological standpoint, depression is often characterized by sleep disturbances, loss of energy, and general fatigue (American Psychiatric Association, 2013; Kovacs, 1985), and anxiety is similarly characterized by restless arousal and tension, difficulty concentrating, and trouble sleeping (American Psychiatric Association, 2013; Dahl \& Lewin, 2002; Reynolds, \& Richmond, 1978), all of which are likely to hamper school performance.

Additionally, the stress generation hypothesis suggests that individuals who experience internalizing symptomatology tend to encounter subsequent stressful events because they select into stressful situations and because their interpersonal styles evoke stress in their ongoing relationships (Hammen, 2005); longitudinal analyses have supported this proposition for adolescents experiencing both depression and anxiety (Cole et al., 2006; Harkness \& Stewart, 2009; Uliaszek et al., 2012). Heightened life stress resulting from the motivational, cognitive, and biological impairments inherent to internalizing symptomatology will likely disrupt adolescents' ability to succeed in achievement-related contexts.

\section{Do Academic Achievement and Internalizing Symptomatology Simultaneously Predict}

\section{Each Other?}

Several studies have previously examined bi-directional prospective relations between internalizing symptomatology and academic achievement in adolescence, all of which have operationalized internalizing symptomatology by measuring depression. First, Grimm (2007) 
assessed depression and standardized vocabulary test performance annually from ages 8 to 14 ; he found support for the academic performance to depression relation, but not for the depression to academic performance relation. Second, Hishinuma and colleagues (2012) assessed depression and self-reported GPA annually throughout high school; they found that depression negatively predicted changes in GPA, but did not find support for the GPA to depression relation. Third, Verboom, Sijtsema, Verhulst, Penninx, and Ormel (2014) assessed students' depression and achievement biennially three times from late childhood into adolescence (ages 10-18), and assessed achievement through teachers' ratings of students' work pace, effort, and performance; they found a negative relation between depression and achievement in both directions for females but not males. Finally, Owens, Shippee, and Hensel (2008) assessed high school students' depression and self-reported GPA from freshman through senior years; they found no support for prospective relations in either direction.

It is too early to draw conclusions regarding these prospective relations, given the sparse existing evidence, and the way that academic achievement has been assessed in prior studies. Specifically, achievement has been operationalized using a) self-reports of GPA, b) composite teacher perceptions of student achievement that include effort and pace, as well as achievement, or c) performance on a standardized vocabulary test. Self-reported GPA and actual GPA from official school records are often discrepant (students in general tend to over-state their actual GPA, but depressed students tend to under-state it; Gramzow, Elliot, Asher, \& McGregor, 2003; Zimmerman, Caldwell, \& Bernat, 2002), composite teacher reports likely contain information beyond student achievement per se, and performance on a standardized test in one specific domain at one time point is likely a constricted indicator of students' academic achievement (i.e., it does not reflect a students' ability to engage and persist in school assignments, studying, note- 
taking, and classroom learning over an extended period of time). A longitudinal study using both official school GPA data and internalizing symptomatology has yet to be conducted.

\section{The Present Research}

In the present research, we tested the bi-directional prospective relations between internalizing symptomatology and academic performance using a sample of students from Western New York who were followed from $6^{\text {th }}$ through $10^{\text {th }}$ grade. To assess internalizing symptomatology, students provided annual reports of depression and anxiety at the beginning of each school year. To assess academic achievement, students' GPA for each school year was obtained from official school records at the end of the year. To test the bi-directional prospective relations, we started with model comparisons to determine the longitudinal model that best described the data - a bivariate autoregressive model (bivariate ARM; Finkel, 1995) or a bivariate autoregressive latent trajectory model (bivariate ALTM; Bollen \& Curran, 2004; Curran \& Bollen, 2001). We then examined the bi-directional prospective relations between internalizing symptomatology (represented by either depression or anxiety) and academic achievement (represented by GPA). We also conducted ancillary analyses that tested the same model using PA and NA (instead of depression and anxiety), and the same model while using PA and NA as covariates, to determine whether any findings observed were simply a function of general levels of PA and/or NA (Podsakoff, MacKenzie, Lee, \& Podsakoff, 2003; Watson \& Pennebaker, 1989).

The bivariate ARM posits autoregressive processes and fixed cross-lagged effects, which examine the effect of a predictor variable at Time $t$ - 1 on the level of a criterion variable at Time $t$, controlling for the level of the criterion variable at Time $t$-1. In the present study, we examined cross-lagged paths running from internalizing symptomatology to GPA assessed the same year, 
rather than GPA assessed the subsequent year. We used this approach given that internalizing symptomatology was assessed at the beginning of each school year and, therefore, was most pertinent to predicting academic achievement over the 7 to 9 month period that followed. We examined cross-lagged paths running from GPA to internalizing symptomatology the subsequent year given that internalizing symptomatology was assessed 3 to 5 months following the end of the assessment period for prior year GPA.

The bivariate ALTM is a hybrid of a bivariate ARM and a bivariate latent growth curve model, the latter of which models each variable as a function of the intercept factor (i.e., initial level) and slope factors (i.e., growth; McArdle, 1988; McArdle \& Anderson, 2000), and therefore captures a different aspect of longitudinal data than the ARM. The ALTM therefore captures year-to-year and stable growth processes by positing both autoregressive and crosslagged effects, as well as intercept and slope factors (see Figure 1), allowing simultaneous estimation of the model parameters. ${ }^{2}$ To avoid possible statistical bias in the ALTMs, as recommended by Bollen and Curran (2004; see also Curran \& Bollen, 2001), the first measurement point is treated as predetermined (i.e., as an exogenous variable not influenced by the trajectory factors or the other measurement points), but is correlated with the latent intercept and slope parameters. Critical model parameters of the autoregressive component in the ALTM (i.e., autoregression effects, cross-lagged effects) are estimated while controlling for the growth curve component (i.e., intercept, slope) and vice versa; in other words, ALTM addresses potential confounding in estimates between autoregressive and growth parameters, resulting in ALTM parameter estimates that are not always the same as (or even close to) those in ARM.

We fit separate models in which depression and anxiety each represented internalizing symptomatology. Prospective effects of internalizing symptomatology on GPA, and of GPA on 
internalizing symptomatology, would manifest in negative, significant cross-lags from one variable (e.g., depression) in year one to the other variable (e.g., GPA) in the following year. Based on the conceptual arguments reviewed above and our improved measurement of academic achievement, we predicted that bi-directional prospective relations would emerge. Additionally, we expected that bi-directional prospective relations would not emerge when PA and NA were substituted for internalizing symptomatology in our models, but that they would continue to emerge when PA and NA were controlled for at each measurement point, indicating that our effects were due to internalizing symptomatology, and not general affect.

\section{Method}

\section{Participants}

A total of 130 students participated (sixth grade age: $M=11.17, S D=.38 ; 40.2 \%$ female; 92.4\% White, 3.8\% Black, 1.5\% Hispanic, 2.3\% Asian). Retention rates were 98\% or above for each year of the study $(n s=128-130)$. This sample size was based on the maximum number of participants that could be recruited during the initial year of data collection, and subsequently retained over the duration of the study. No manipulations and no data exclusions were used in the current research and all variables that were analyzed for this research are reported.

\section{Procedure}

This research was part of a larger longitudinal study of competence and motivation conducted in the Rush-Henrietta Central School District. Participants were initially recruited at the beginning of the first grade school year and periodic assessments were conducted until tenth grade. The present research focuses on an intensive period of assessment that took place annually during the junior high and high school years of early adolescence, specifically in grades 6 through 10. These primary assessment years took place from 2003 to 2008. The majority of the 
students attended one of two public junior high schools that fed into a public senior high system beginning in $9^{\text {th }}$ grade. A minority of students attended junior and/or senior high at parochial schools or were home schooled. All procedures were approved by the University of Rochester Institutional Review Board.

Pairs of trained female research assistants visited participants in their homes to conduct assessments during the first few months of the school year (i.e., late September to mid November); October was the modal assessment time point across study years. During these sessions, participants completed the measures of internalizing symptomatology in a private room, and were ensured by the research assistant that every effort would be made to keep their responses confidential. Research assistants read all questions and participants marked their responses on answer sheets from behind a cardboard barrier, after which participants placed their responses in an envelope that was then sealed by the research assistant. Participants were provided with monetary compensation after the completion of each assessment. Academic achievement data was acquired from official school records after the end of the school year.

\section{Measures}

\section{Internalizing Symptomatology}

Depression. Depression was assessed using the 27-item Children's Depression Inventory (CDI: Kovacs, 1985).We omitted the suicide item from the assessment due to concerns about child, parent, and administration sensitivity. The items focused on specific depressive symptoms experienced over the past few months (e.g., feeling sad, feeling like crying, feeling alone). Each item had three response options-with 0 indicating least severe depressive symptoms and 2 indicating most severe depressive symptoms - and participants were instructed to pick the one that best described them (e.g., $0=$ "I am sad once in a while," 1 = "I am sad many times," 2 = "I 
am sad all the time"; $\alpha \mathrm{s}=.85-.92$ ). The symptoms captured in the CDI are similar to those included in the DSM-V diagnostic category of Major Depressive Disorder (American Psychiatric Association, 2013).

Anxiety. Anxiety was assessed using the 28-item Revised Children's Manifest Anxiety Scale (RCMAS: Reynolds \& Richmond, 1978). The items focused on physiological symptoms (e.g., "I wiggle in my seat a lot"; "I am tired a lot"), worry and oversensitivity (e.g., "I get nervous when things do not go the right way for me"; "I worry about what is going to happen"), and fear and difficulty concentrating (e.g., "It's hard for me to keep my mind on my school work"; "Others seem to do things easier than I can") experienced over the past few months. Participants responded to the items using a dichotomous scale $(0=$ "no"; $1=$ "yes"; $\alpha \mathrm{s}=.89$ .92). The symptoms captured in the RCMAS are similar to those included in the DSM-V diagnostic category of Generalized Anxiety Disorder (American Psychiatric Association, 2013).

\section{GPA}

Yearly grade reports for each student were acquired directly from participants' schools at the end of each school year. A composite yearly grade point average (GPA) was calculated using the mean of a given students' yearly grades in English, math, history/social studies, and science ( $\alpha \mathrm{s}=.91$ to .96$)$. Grades were scored on a $0-100 \%$ scale; however, to bring the scale of GPA more in line with that of depression and anxiety, we divided all GPA scores by 10, yielding a new scale of $0-10 .^{3}$

\section{Covariates}

Positive and negative affect. Positive affect (PA) and negative affect (NA) were assessed using the 27-item Positive and Negative Affect Schedule-Children's Version (PANAS-C: Laurent et al., 1999). The 12 PA and 15 NA items focused on moods (e.g., PA: "joyful," "calm," 
"proud;" NA: "sad," "frightened," "ashamed") experienced over the past few months.

Participants responded to the items using a 1 (very slightly or not at all) to 5 (extremely) scale $(\alpha \mathrm{s}=.88-.94$ and $.91-.94$ for PA and NA, respectively).

\section{Results}

Table S1 in online supplement displays descriptive statistics and zero-order correlations involving the study variables. Depression and anxiety assessed in the same year correlated .76 to $.84(p s<.05)$. Depression and anxiety correlated .69 to .77 with NA assessed in the same year, and -.28 to -.70 with PA assessed in the same year $(p s<.05)$. NA and PA assessed in the same year correlated -.28 to $-.50(p s<.05)$.

Throughout, we evaluated model fit based on three indices: the chi-square test of exact fit, the comparative fit index (CFI), the Tucker-Lewis Index (TLI), and the root mean square error of approximation (RMSEA). CFI, TLI, and RMSEA are often preferable to the chi-square test when evaluating model fit, because, whereas the latter becomes more sensitive to model misfit as sample size increases, the former are influenced to a much smaller degree by sample size. CFI values equal to or above .95 , TLI values equal to or above .95 , and RMSEA values equal to or below .08 were taken to indicate good model fit (Kline, 2010). When comparing the fit of different models, we employed the Akaike Information Criterion (AIC). We report unstandardized estimates for ease of interpretation. We applied the full information maximum likelihood method to address missing data (Enders, 2006).

\section{Measurement Invariance}

Given our interest in assessing internalizing symptomatology across multiple time points, we sought to establish longitudinal measurement invariance for the CDI and RCMAS across the five study years (Vandenberg and Lance, 2000). To facilitate this test, and ensure model 
convergence, we created four item parcels for each scale, each consisting of 6-7 items, by selecting every fourth item for inclusion in the same parcel (e.g., CDI items 1, 5, 9, 13, etc., were included in parcel 1). Our test involved two steps: a) establishing configural invariance (i.e. that each construct has an identical factor structure at each time point); and b) establishing metric invariance (i.e. that each construct has identical factor loadings at each time point). These two steps are important to ensure that relations among constructs at each time point do not spuriously vary due to measurement non-invariance (Chen, 2008).

First, to establish configural invariance, for both CDI and RCMAS, we fit a model with five separate one-factor models, each representing one assessment year. Each one-factor model was defined by the four item parcels from that assessment year; residuals for different items assessed at the same time point were allowed to correlate, and the first loading of each factor was fixed to 1 to identify the model. The configural invariance model showed good fit for both scales $\left(\mathrm{CDI}: \chi^{2}(120)=195.54, p<.001, \mathrm{CFI}=.96 ; \mathrm{TLI}=.94 ; \mathrm{RMSEA}=.07 ; \mathrm{RCMAS}: \chi^{2}(120)=\right.$ $160.68, p<.001, \mathrm{CFI}=.98 ; \mathrm{TLI}=.97 ; \mathrm{RMSEA}=.05)$, suggesting that each construct had equivalent structure across study years. Second, to establish metric invariance, we re-ran the same models, while fixing loadings on the same item to be equal across time points (e.g., the loading for CDI item parcel 1 in grade 6,7,8,9, and 10); these scalar invariance models again showed good fit for both scales $\left(\mathrm{CDI}: \chi^{2}(132)=225.50, p<.001, \mathrm{CFI}=.95\right.$; TLI $=.92$; RMSEA $=.08 ;$ RCMAS: $\chi^{2}(132)=177.47, p<.001, \mathrm{CFI}=.98 ; \mathrm{TLI}=.97 ;$ RMSEA $\left.=.05\right)$, suggesting that the items on each construct had equivalent loadings across time points. Notably, a chi-square difference test between the configural and metric invariance models was significant for the CDI $\left(\chi^{2}(12)=29.96, p=.003\right)$, but not the RCMAS $\left(\chi^{2}(12)=16.79, p=.16\right)$, suggesting that fixing the loadings to be equal across time points resulted in slightly worse fit of the CDI model, but 
not the RCMAS model. However, the overall good fit of the configural and metric invariance models for both scales gives us confidence in each measure's invariance across time.

\section{Model Comparison}

Table 1 reports model fit statistics for all examined models. We first tested the fit of the bivariate ARM model, as well as the BALT model. For both depression and anxiety, the ARM did not fit the data particularly well (depression: $\chi^{2}(28)=75.80, p<.001, \mathrm{CFI}=.96$; TLI $=.93$; RMSEA $=.12 ;$ AIC $=523.38 ;$ anxiety $: \chi^{2}(28)=77.54, p<.001$, CFI $=.96 ;$ TLI $=.94 ;$ RMSEA $=.12 ; \mathrm{AIC}=304.12$ ), indicating that models with only autoregressive and cross-lagged processes do not comprehensively explain the data.

We next tested the bivariate ALTM model. We initially found that a model including the autoregressive effects did not yield an appropriate solution for both the anxiety and depression models, and most of the autoregressive effects were not statistically significant; we therefore fixed the autoregressive component in ALTM to zero in all subsequent models (see Curran \& Bollen, 2001, for a similar model constraint). The subsequent bivariate ALTM showed a good fit for both depression and anxiety (depression: $\chi^{2}(22)=35.78, p=.03$, CFI $=.99$, TLI $=.98$; $\mathrm{RMSEA}=.07 ; \mathrm{AIC}=487.69 ;$ anxiety: $\chi^{2}(22)=30.01, p=.12, \mathrm{CFI}=.99 ; \mathrm{TLI}=.99 ; \mathrm{RMSEA}$ $=.05 ; \mathrm{AIC}=257.34)$. Notably, for both depression and anxiety, the AIC indicated that the bivariate ALTM was the best model to account for the data, compared to the ARM. Overall, these results suggest that a combination of cross-lagged and growth effects are operative in the data, highlighting the necessity of using the ALTM to examine the bi-directional prospective relations between internalizing symptomatology and academic achievement.

To further explore the best description of the data within ALTM, we imposed equality constraints on the (non-standardized) cross-lagged effects over time, and examined whether these 
constraints worsened model fit. The results showed that imposing equality constraints on the effect of GPA on the internalizing symptomatology variable did not significantly worsen the fit $\left(\right.$ depression; $\chi^{2}(3)=1.82, p=.61$, anxiety; $\left.\chi^{2}(3)=4.78, p=.19\right)$, whereas imposing equality constraints on the effect of the internalizing symptomatology variable on GPA significantly worsened the fit (depression; $\chi^{2}(3)=23.88, p<.01$, anxiety; $\left.\chi^{2}(3)=21.49, p<.01\right)$. These findings suggest that, in light of model parsimony, it is reasonable to assume that the crosslagged effects of GPA on depression and anxiety are not different across time points, but that the cross-lagged effects of depression and anxiety on GPA do differ at different time points. Table 2 presents the parameter estimates in the final bivariate ALTMs for depression and anxiety, and Table S2 in the online supplement presents descriptive statistics for latent intercepts and slopes.

\section{Does Internalizing Symptomatology Affect Subsequent Academic Achievement?}

Depression negatively predicted GPA in grade $7(b=-.48, p<.05)$, grade $9(b=-.29, p$ $=.06)$, and grade $10(b=-.66, p<.01)$, but not in grade $8(b=-.13, p=.35)$. Anxiety negatively predicted GPA in grade $7(b=-.55, p=.06)$, grade $9(b=-.47, p<.05)$, and grade $10(b=-.75, p$ $<.01)$, but not in grade $8(b=-.21, p=.29)$. These findings suggest that students who showed increased markers of internalizing symptomatology at the beginning of a school year exhibited decreased academic performance over the course of that school year, although these effects were more consistent during the high school years than the junior high school years.

\section{Does Academic Achievement Affect Subsequent Internalizing Symptomatology?}

GPA negatively predicted internalizing symptomatology across all school years (depression: $b \mathrm{~s}=-.14, p s=.005$; anxiety: $b \mathrm{~s}=-.136, p s=.001$ ). Because the model with equality constraints was supported, the magnitude of the effect is considered consistent over time. These results indicate that students who experienced a lack of academic success during one school year 
showed elevated internalizing symptomatology at the beginning of the following school year, and that this effect stayed consistent as students progressed to more advanced levels of education.

\section{Ancillary Analyses}

To address the possibility that variation in internalizing symptomatology could be accounted for by variation in general affect, we conducted several ancillary analyses (see Table 2 for parameter estimates, and Table S2 for descriptive statistics for latent variables). First, we replaced depression and anxiety with PA or NA in the final ALTM. These new models showed good fit both for PA and NA $\left(\mathrm{PA}: \chi^{2}(25)=33.81, p=.11, \mathrm{CFI}=.99, \mathrm{TLI}=.99 ; \mathrm{RMSEA}=.05\right.$; $\left.\mathrm{NA}: \chi^{2}(25)=18.43, p=.82, \mathrm{CFI}=1.00 ; \mathrm{TLI}=1.01 ; \mathrm{RMSEA}=.00\right)$, indicating that the trajectory of PA and NA are best described by the combination of latent growth curve and autoregression (i.e., by an ALTM) models. Importantly, unlike the models for depression and anxiety, none of the cross-lagged effects of PA or NA on GPA were statistically significant $(b$ s $=$ -.04 to .00 for PA, and -.11 to .02 for NA), and none of the cross-lagged effects of GPA on PA or NA were statistically significant $(b s=.18$ for PA and .19 for NA).

Second, we re-ran our primary ALTMs for depression and anxiety, using both PA and NA separately as time-varying covariates. Specifically, for each model, both the internalizing symptomatology variable and GPA were regressed on the covariate for that same year (e.g., in one model, grade 7 depression and GPA were regressed on grade 7 negative affect). ${ }^{4}$ All four models showed reasonably good fit, though worse than for our primary models, primarily when negative affect was used as a covariate (depression/NA: $\chi^{2}(57)=136.25, p<.001, \mathrm{CFI}=.95$, $\mathrm{TLI}=.92 ; \mathrm{RMSEA}=.11 ;$ anxiety/NA: $\chi^{2}(63)=158.49, p<.001, \mathrm{CFI}=.94, \mathrm{TLI}=.92 ; \mathrm{RMSEA}$ $=.11$; depression/PA: $\chi^{2}(57)=101.19, p<.001, \mathrm{CFI}=.97, \mathrm{TLI}=.95 ; \mathrm{RMSEA}=.08$; 
anxiety/PA: $\left.\chi^{2}(57)=90.03, p<.01, \mathrm{CFI}=.98, \mathrm{TLI}=.96 ; \mathrm{RMSEA}=.07\right)$. Importantly, the pattern of bi-directional prospective effects remained relatively unchanged (see Table 2). When PA and NA were each controlled separately, both depression $(b \mathrm{~s}=-.19$ to -.89$)$ and anxiety $(b \mathrm{~s}=$ -.19 to -.64) continued to exert moderate, negative effects on subsequent-year GPA, and these effects were of similar magnitude to those in our primary analyses. Similarly, GPA continued to exert a negative effect on same-year internalizing symptomatology (depression: $b \mathrm{~s}=-.08$; anxiety: $b$ s $=-.06$ to -.09 ), although these effects were somewhat attenuated compared to our primary analyses.

Taken together, these findings suggest that the cross-lagged effects of internalizing symptomatology on GPA, and those of GPA on depression and anxiety, were not simply a function of general affect. Notably, for the analyses in which general affect was treated as a covariate, due to strong correlations between depression, anxiety, and general affect, as well as the large number of variables in these models, parameter estimates were relatively unstable. As a result, the significance values of both sets of bi-directional prospective effects were somewhat larger in these models, compared to the models in our primary analyses, even though the magnitude of many of these same paths increased substantially in size. We therefore urge caution in interpreting specific effect sizes in these ancillary analyses, and instead view the overall pattern of effects as indicating that the observed bi-directional prospective effects are due primarily to internalizing symptomatology, not general affect. ${ }^{5}$

\section{Discussion}

The present study provides the most rigorous longitudinal evidence to date that elevated internalizing symptomatology predicts poor downstream academic achievement as measured by concrete performance indices (i.e., grades), and that poor academic achievement in turn predicts 
elevated internalizing symptomatology. We conducted a five-year examination of the relations between internalizing symptomatology and academic achievement from $6^{\text {th }}$ to $10^{\text {th }}$ grade, and found that bi-directional prospective relations emerged; depression and anxiety at the beginning of a school year negatively predicted GPA during that school year, and GPA in any given school year negatively predicted depression and anxiety at the beginning of the following year. Importantly, when general affect was substituted for depression and anxiety in our models, bidirectional prospective effects did not emerge with academic performance; in contrast, these effects did continue to emerge when general affect was controlled for in our models that included depression and anxiety. The lack of significant prospective effects running from general affect to GPA, and GPA to general affect, likely reflects the fact that general affect constitutes only one of many symptoms of depression and anxiety that could lead to or reflect poor academic performance. Although poor performing students are likely to feel bad, and these negative emotions could further hamper achievement pursuits, the full suite of motivational, cognitive, and biological symptoms manifested in depression and anxiety are likely to cumulatively have a greater impact on academic functioning.

\section{Internalizing Symptomatology and Academic Achievement: A Two-Way Street}

Prior research on the relation between internalizing symptomatology and academic performance in adolescence has primarily examined concurrent relations (Hishinuma et al., 2012; Siepp, 1991), and longitudinal work in this domain has mostly been unidirectional, despite theorists contending that such effects cut both ways and snowball over time (Roeser, Eccles, \& Sameroff, 1998; Rudolph, 2004). In the present study, we found support for bi-directional effects, though the link from achievement to internalizing symptomatology was more consistent than the link from internalizing symptomatology to achievement. In the former case, the effects 
were of equivalent magnitude across the junior and senior high school years; in the latter case, the effects were somewhat larger in the senior high school years than the junior high school years. In neither instance did the effects systematically increase or decrease over time.

Our findings linking poor academic achievement to subsequent increases in depression and anxiety provide strong empirical support for theories that view stressful life events as precipitating agents in the onset of internalizing symptomatology (Brown \& Harris, 1978; Hammen, 2005; Hudson \& Rapee, 2004; Monroe \& Reid, 2009). Our findings linking elevated internalizing symptomatology to diminished academic performance provide strong empirical evidence that depression and anxiety cause motivational, cognitive, and biological impairment, which in turn can degrade achievement-related functioning (Eysenck et al., 2007; Gotlib \& Joorman, 2010; Nolen-Hoeksema et al., 2008; Strauman, 2002). These types of co-occurring directional effects have been labeled variously as transactional effects, chain reactions, cascade effects, and snowball effects (Obradović, Burt, \& Masten, 2010); establishing these effects together in reciprocal fashion therefore supports developmental theories proposing that distinct domains of psychological functioning are related to one another over time (Cicchetti \& Schneider-Rosen, 1986; Masten et al., 2005; Rutter, Kim-Cohen, \& Maughan, 2006).

The emergence of year-to-year cascade effects in the present study is important given that some of the observed prospective effects were relatively modest in size (similar to prior work; Grimm, 2007; Hishinuma et al., 2012; Owens et al., 2008; Verboom et al., 2014). In isolation, any one of the observed prospective effects may not portend strong implications for adolescent emotional health. However, taken together, these prospective effects suggest that students suffering from poor academic performance may experience a repeated, annual decrement in emotional health, which over the course of junior high and early high school may lead to 
substantial internalizing symptomatology. The cascade effects running from internalizing symptomatology to GPA have similar, but less dramatic, implications, given that they were not as consistent over time.

There are likely two reasons why our study uncovered bi-directional, prospective relations between internalizing symptomatology and academic achievement, whereas other studies (e.g., Grimm, 2007; Hishinuma et al., 2012) have not. First, prior studies have relied on self-reported GPA, teacher evaluations that included content beyond achievement, or performance on a vocabulary test occurring at one time point, whereas the present research utilized annual GPA from official school records. Second, the transitions from elementary school to junior high school and from junior high school to high school are marked by numerous academic challenges (e.g., increased work load, complex subject material, salient competition with peers; Benner, 2011), and these challenges can strain children's coping resources and can increase the likelihood of both academic and mental health difficulties (Alspaugh, 1998; Greene \& Ollendick, 1993; Isakson \& Jarvis, 1999). The prior studies that have been conducted on adolescents' internalizing symptomatology and academic performance either have taken place across either of these major school transitions (Hishunuma et al., 2012; Owens et al., 2008), have taken place across only one of these transitions (Grimm, 2007), or have not utilized annual assessment periods (Verboom et al., 2014). The present research utilized annual assessments across both of the major school transitions; the first year of our study corresponded to students' first year in middle school (i.e., grade 6), and the fourth year of our study corresponded to students' first year in high school (i.e., grade 9). The increased challenges and stressors encountered by students during these transitions may have made for a particularly sensitive and powerful test of the hypothesized bi-directional prospective effects. 


\section{Depression and Anxiety: Similar or Different Links with Academic Achievement?}

Although not identical, the observed results for depression and anxiety were quite similar.

On one hand, this is to be expected, given that both depression and anxiety are thought to represent a common class of internalizing psychopathology (Kendler et al., 2003; Kruger, 1999; Watson, 2005), and they show considerable comorbidity in adolescence (Cummings, Caporino, \& Kendall, 2014; Garber \& Weersing, 2010). Additionally, commonly used self-report measures of depression and anxiety, including the RCMAS and CDI used in the present investigation, pick up on similar symptoms (Seligman, Ollendick, Langley, \& Baldacci, 2004), in part due to some conceptual overlap among their items (Seligman \& Ollendick, 1998). However, despite their commonalities, depression and anxiety are thought to be distinct motivationally (e.g., the former is grounded in low approach motivation and high avoidance motivation, whereas the latter is primarily grounded in high avoidance motivation; Derryberry \& Reed, 2002; Dickson \& MacLeod, 2004; Strauman, 2002), cognitively (e.g., the former typically involves rumination about imminent sorrows, whereas the latter typically involves vigilance for future threat; Gotlib \& Joorman, 2010; Eysenck et al., 2007), and affectively (the former is experienced as sadness and despair, whereas the latter is experienced as worry and apprehension; Blumberg \& Izard, 1986; Higgins, 2013). Further research is should therefore investigate possible differential links between these two forms of emotional distress and psychological functioning in adolescence.

\section{Limitations}

The present research has several limitations. First, although our study was methodologically rigorous and powerful in the sense that it consisted of five annual assessments across two major school transitions, the sample comprised a relatively modest number of participants. Second, the participants in our sample were quite uniform with regard to ethnic and 
socioeconomic background, with middle class Caucasian youth being overrepresented. Third, GPA, especially as assessed via official school records, is a critical marker of academic achievement, but other markers of academic competence (e.g., attendance, creativity) and competence more broadly (e.g., social competence, competence in extracurricular activities) also carry valuable information. Future research utilizing a larger and more diverse sample and including a more diverse set of competence-relevant outcome measures would be welcomed.

Fourth, although our research harnessed both a longitudinal methodology and advanced modeling techniques to attempt to isolate causal prospective effects, the data we present are still fundamentally correlational, and we therefore cannot conclude that poor academic performance directly caused elevated internalizing symptomatology, or vice versa. In light of prior work suggesting that interpersonal stressful life events are the most common precipitants of internalizing symptomatology (Brown et al., 1987; Hammen, 2005; Kendler et al., 2003), it is likely that academic achievement is only one of multiple factors that precipitate or result from elevated internalizing symptomatology. It would therefore be premature to conclude based on these findings that the best strategy to ward off internalizing symptomatology in adolescence is to merely give students good grades regardless of their performance, particularly given that feelings of genuine autonomy and competence during goal pursuit are critical ingredients to fostering well-being (Ryan \& Deci, 2000; see Baumeister, Campbell, Krueger, \& Vohs, 2003, for a similar argument). Additionally, if all students are given bonus points in an effort to inflate their grades, students who are performing poorly relative to their peers may continue to perceive their achievement progress as lacking.

\section{Conclusion}


Adolescence is a challenging time for youth, as they experience many physical and psychological changes and face several normative life tasks and transitions that can be difficult to navigate. Prior work has indicated that many adolescents are struggling with respect to mental health and academic proficiency, yet little rigorous, longitudinal research has been conducted to understand the interrelations between these important markers of psychological functioning. The present research sought to address this oversight, and our results provide evidence for bidirectional prospective links between internalizing symptomatology and academic achievement. These findings highlight the importance of adopting an integrated approach to adolescent development and, we hope, serve as an impetus for additional empirical and theoretical work in this important area of inquiry. 


\section{References}

Allen, J. L., Rapee, R. M., \& Sandberg, S. (2008). Severe life events and chronic adversities as antecedents to anxiety in children: A matched control study. Journal of Abnormal Child Psychology, 36, 1047-1056.

Alspaugh, J. W. (1998). Achievement loss associated with the transition to middle school and high school. Journal of Education Research, 92, 20-25.

American Psychiatric Association. (2013). Diagnostic and statistical manual of mental disorders (5th ed.). Washington, DC.

Aud, S., Hussar, W., Johnson, F., Kena, G., Roth, E., Manning, E., ... \& Zhang, J. (2012). The condition of education. US Department of Education, National Center for Education Statistics. Washington, DC. Retrieved 30 January 2014 from http://nces.ed.gov.

Bandura, A. (1986). Social foundations of thought and action: A social cognitive theory. Englewood Cliffs, NJ: Prentice-Hall.

Bandura, A., Pastorelli, C., Barbaranelli, C., \& Caprara, G. V. (1999). Self-efficacy pathways to childhood depression. Journal of Personality and Social Psychology, 76, 258-269.

Baumeister, R. F., Campbell, J. D., Krueger, J. I., \& Vohs, K. D. (2003). Does high self-esteem cause better performance, interpersonal success, happiness, or healthier lifestyles? Psychological Science in the Public Interest, 4, 1-44.

Benner, A. D. (2011). The transition to high school: Current knowledge, future directions. Educational Psychology Review, 23, 299-328.

Blumberg, S. H. \& Izard, C. E. (1986). Affective and cognitive characteristics of depression in 10- and 11-year olds. Journal of Personality and Social Psychology, 49, 194-202. 
Blyth, D. A., Simmons, R. G., \& Carlton-Ford, S. (1983). The adjustment of early adolescents to school transitions. Journal of Early Adolescence, 3, 105-120.

Bollen, K. A. \& Curran, P. J. (2004). Autoregressive latent trajectory (ALT) models: A synthesis of two traditions. Sociological Methods \& Research, 32, 336-383.

Brown, G. W., Bifulco, A., \& Harris, T. O. (1987). Life events, vulnerability, and onset of depression: Some refinements. British Journal of Psychiatry, 150, 30-42.

Brown, G. W., Bifulco, A., Harris, T., \& Bridge, L. (1986). Life stress, chronic subclinical symptoms, and vulnerability to clinical depression. Journal of Affective Disorders, 11, 119.

Brown, G. W. \& Harris, T. O. (1978). Social origins of depression. London, UK: Tavistock.

Chen, F. F. (2008). What happens when we compare chopsticks with forks? The impact of making inappropriate comparisons in cross-cultural research. Journal of Personality and Social Psychology, 95, 1005-1018.

Cicchetti, D. \& Schneider-Rosen, K. (1986). An organizational approach to childhood depression. In M. Rutter, C. Izard, \& P. Read (Eds.), Depression in young people: Developmental and clinical perspectives (pp. 71-134). New York, NY: Guilford Press.

Cole, D. A., Nolen-Hoeksema, S., Girgus, J., \& Paul, G. (2006). Stress exposure and stress generation in child and adolescent depression: A latent state-trait-error approach to longitudinal analyses. Journal of Abnormal Psychology, 115, 40-51.

Cummings, C. M., Caporino, N. E., \& Kendall, P. C. (2014). Comorbidity of anxiety and depression in children and adolescents: 20 years after. Psychological Bulletin, 140, 816845. 
Curran, P. J. \& Bollen, K. A. (2001). The best of both worlds: combining autoregressive and latent curve models. In L.M. Collins \& A.G. Sayer (Eds.), New methods for the analysis of change (pp. 107-135). Washington D.C.: APA.

Dahl, R. E., \& Lewin, D. S. (2002). Pathways to adolescent health: Sleep regulation and behavior. Journal of Adolescent Health, 31, 175-184.

Derryberry, D. \& Reed, M. A. (2002). Anxiety-related attentional biases and their regulation by attentional control. Journal of Abnormal Psychology, 111, 225-236.

Dickson, J. M. \& MacLeod, A. K. (2004). Anxiety, depression, and approach and avoidance goals. Cognition and Emotion, 18, 423-430.

Elliot, A. J. \& Church, M. A. (1997). A hierarchical model of approach and avoidance achievement motivation. Journal of Personality and Social Psychology, 72, 218-232.

Elliot, A.J., \& Church, M.A. (2003). A motivational analysis of defensive pessimism and selfhandicapping. Journal of Personality, 71, 369-396.

Enders, C.K. (2006). Analyzing structural equation models with missing data. In G.R. Hancock \& R.O. Mueller (Eds.), Structural equation modeling: A second course (pp. 313-342). Greenwich, CT: Information Age Publishing.

Eysenck, M. W., Derakshan, N., Santos, R., \& Calvo, M. G. (2007). Anxiety and cognitive performance: Attentional control theory. Emotion, 7, 336-353.

Finkel, S. E. (1995). Causal analysis with panel data. Thousand Oaks, CA: Sage Publications.

Garber, J. \& Weersing, V. R. (2010). Comorbidity of anxiety and depression in youth: Implications for treatment and prevention. Clinical Psychology: Science and Practice, $17,293-306$. 
Gotlib, I. H. \& Joorman, J. (2010). Cognition and depression: Current status and future directions. Annual Review of Clinical Psychology, 6, 285-312.

Gramzow, R. H., Elliot, A. J., Asher, E., \& McGregor, H. A. (2003). Self-evaluation bias and academic performance: Some ways and some reasons why. Journal of Research in Personality, 37, 41-61.

Greene, R. W. \& Ollendick, T. H. (1993). Evaluation of a multidimensional program for sixthgraders in transition from elementary to middle school. Journal of Community Psychology, 21, 162-176.

Grimm, K. J. (2007). Multivariate longitudinal methods for studying developmental relationships between depression and academic achievement. International Journal of Behavioral Development, 31, 328-339.

Hammen, C. (2005). Stress and depression. Annual Review of Clinical Psychology, 1, 293-319.

Hankin, B. L., Abramson, L. Y., \& Siler, M. (2001). A prospective test of the hopelessness theory of depression in adolescence. Cognitive Therapy and Research, 25, 607-632.

Hankin, B. L., Mermelstein, R., \& Roesch, L. (2007). Sex differences in adolescent depression: Stress exposure and reactivity models. Child Development, 78, 279-295.

Harkness, K. L., Alavi, N., Monroe, S. M., Slavich, G. M., Gotlib, I. H., \& Bagby, R. M. (2010). Gender differences in life events prior to the onset of major depressive disorder: The moderating effect of age. Journal of Abnormal Psychology, 119, 791-803.

Harkness, K. L. \& Stewart, J. G. (2009). Symptom specificity and the prospective generation of life events in adolescence. Journal of Abnormal Psychology, 118, 278-287. 
Harter, S., Whitesell, N. R., \& Kowalski, P. (1992). Individual differences in the effects of educational transitions on young adolescent's perceptions of competence and motivational orientation. American Educational Research Journal, 29, 777-807.

Higgins, E. T. (2013). Beyond pleasure and pain: How motivation works. Oxford, England: Oxford University Press.

Higgins, E. T., Shah, J., \& Friedman, R. (1997). Emotional responses to goal attainment: Strength of regulatory focus as moderator. Journal of Personality and Social Psychology, 72(3), 515-525.

Hishinuma, E. S., Chang, J. Y., McArdle, J. J., \& Hamagami, F. (2012). Potential causal relationship between depressive symptoms and academic achievement in the Hawaiian High School Health Survey using contemporary longitudinal latent variable change models. Developmental Psychology, 48, 1327-1342.

Hudson, J. L. \& Rapee, R. M. (2004). From anxious temperament to disorder: An etiological model of generalized anxiety disorder. In R. G. Heimberg, C. L. Turk, \& D. S. Mennin (Eds.), The etiology and development of generalised anxiety disorder (pp. 51-74). New York, NY: Guilford.

Isakson, K. \& Jarvis, P. (1999). The adjustment of adolescents during the transition into high school: A short-term longitudinal study. Journal of Youth and Adolescence, 28, 1-26.

Kendler, K. S., Hettema, J. M., Butera, F., Gardner, C. O., \& Prescott, C. A. (2003). Life event dimensions of loss, humiliation, entrapment, and danger in the prediction of onsets of major depression and generalized anxiety. Archives of General Psychiatry, 60, 789-796. 
Kendler, K. S., Karkowski, L. M., \& Prescott, C. A. (1999). Causal relationship between stressful life events and the onset of major depression. American Journal of Psychiatry, $156,837-841$.

Kendler, K. S., Prescott, C. A., Myers, J. M., \& Neale, M. C. (2003). The structure for genetic and environmental risk factors for common psychiatric and substance use disorders in men and women. Archives of General Psychiatry, 60, 929-937.

Kline, R. B. (2010). Principles and practices of structural equation modeling ( $3^{\text {rd }}$ ed.). New York, NY: Guilford Press.

Kouros, C. D. \& Garber, J. (2014). Trajectories of individual depressive symptoms in adolescence: Gender and family relationships as predictors. Developmental Psychology, $50,2633-2643$.

Kovacs, M. (1985). The Children's Depression Inventory (CDI). Psychopharmacology Bulletin, 21, 995-998.

Krueger, R. F. (1999). The structure of common mental disorders. Archives of General Psychiatry, 56, 921-926.

Laurent, J., Catanzaro, S. J., Joiner, T. E., Rudolph, K. D., Potter, K. I., Lambert, S., Osborne, L., \& Gathright, T. (1999). A measure of positive and negative affect for children: Scale development and preliminary validation. Psychological Assessment, 11, 326-338.

Masten, A. S., Roisman, G. I., Long, J. D., ..., \& Tellegen, A. (2005). Developmental cascades: Linking academic achievement and externalizing and internalizing symptoms over 20 years. Developmental Psychology, 41, 733-746. 
McArdle, J. J. (1988). Dynamic structural equation modeling of repeated measures data. In R. B. Cattell \& J. Nesselroade (Eds.), Handbook of multivariate experimental psychology (pp. 561-614). New York, NY: Plenum.

McArdle, J. J. \& Anderson, E. (1990). Latent variable growth models for research on aging. In J. E. Birren \& K. W. Schaie (Eds.), Handbook of the psychology of aging, (pp. 21-44). New York, NY: Academic Press.

Merikangas, K. R., He, J., Burstein, M., Swanson, S. A., Avenevoli, S., Cui, L., ... \& Swendsen, J. (2010). Lifetime prevalence of mental disorders in U.S. adolescents: Results from the National Comorbidity Survey Replication-Adolescent Supplement. Journal of the American Academy of Adolescent and Child Psychiatry, 49, 980-989.

Moilanen, K. L., Shaw, D. S., \& Maxwell, K. L. (2010). Developmental cascades: Externalizing, internalizing, and academic competence from middle childhood to early adolescence. Development and Psychopathology, 22, 635-653.

Monroe, S. M. \& Reid, M. W. (2009). Life stress and major depression. Current Directions in Psychological Science, 18, 68-72.

Nolen-Hoeksema, S., Wisco, B. E., \& Lyubomirsky, S. (2008). Rethinking rumination. Perspectives on Psychological Science, 3, 400-424.

Obradović, J., Burt, K. B., \& Masten, A. S. (2010). Testing a dual cascade model linking competence and symptoms over 20 years from childhood to adulthood. Journal of Clinical Child and Adolescent Psychology, 39, 109-117.

Oertig, D., Schüler, J., Schnelle, J., Brandstätter, V., Roskes, M., \& Elliot, A. J. (2013). Avoidance goal pursuit depletes self-regulatory resources. Journal of Personality, 81, $365-375$. 
Osborne, J. W. (1997). Race and academic disidentification. Journal of Educational Psychology, $89,728-735$.

Owens, T. J., Shippee, N. D., \& Hensel, D. J. (2008). Emotional distress, drinking, and academic achievement across the adolescent life course. Journal of Youth and Adolescence, 37, $1242-1256$.

Podsakoff, P. M., MacKenzie, S. B., Lee, J. Y., \& Podsakoff, N. P. (2003). Common method biases in behavioral research: A critical review of the literature and recommended remedies. Journal of Applied Psychology, 88, 879-903.

Reynolds, C. R., \& Richmond, B. O. (1978). What I think and feel: A revised measure of children's manifest anxiety. Journal of Abnormal Child Psychology, 6, 271-280.

Roeser, R. W., Eccles, J. S., \& Sameroff, A. J. (1998). Academic and emotional functioning in early adolescence: Longitudinal relations, patterns, and prediction by experience in middle school. Development and Psychopathology, 10, 321-352.

Rudolph, K. D., (2004). A self-regulation approach to understanding adolescent depression in the school context. In T. Urdan \& F. Pajares (Eds), Educating adolescents: Challenges and strategies (pp. 33-64). Greenwich, CT: Information Age.

Rudolph, K. D., Flynn, M., Abaied, J. L., Groot, A., \& Thompson, R. (2009). Why is past depression the best predictor of future depression? Stress generation as a mechanism of depression continuity in girls. Journal of Clinical Child and Adolescent Psychology, 38, 473-485.

Rutter, M., Kim-Cohen, J., \& Maughan, B. (2006). Continuities and discontinuities in psychopathology between childhood and adult life. Journal of Child Psychology and Psychiatry, 47, 276-295. 
Ryan, R. M. \& Deci, E. L. (2000). Self-determination theory and the facilitation of intrinsic motivation, social development, and well-being. American Psychologist, 55, 68-78.

Saluja, G., Iachan, R., Scheidt, P. C., Overpeck, M. D., Sun, W., \& Geidd, J. N. (2004). Prevalence of and risk factors for depressive symptoms among young adolescents. Archives of Pediatric Adolescent Medicine, 158, 760-765.

Seipp, B. (1991). Anxiety and academic performance: A meta-analysis of findings. Anxiety Research, 4, 27-41.

Seligman, L. D. \& Ollendick, T. H. (1998). Comorbidity of anxiety and depression in children and adolescents: An integrative review. Clinical Child and Family Psychology Review, 1, $125-144$.

Seligman, L. D., Ollendick, T. H., Langley, A. K., \& Baldacci, H. B. (2004). The utility of measures of child and adolescent anxiety: A meta-analytic review of the Revised Children's Manifest Anxiety Scale, the State-Trait Anxiety Inventory for Children, and the Child Behavior Checklist. Journal of Clinical Child and Adolescent Psychology, 33, $557-565$.

Shankman, S. A., Klein, D. N., Tenke, C. E., \& Bruder, G. E. (2007). Reward sensitivity in depression: A biobehavioral study. Journal of Abnormal Psychology, 116, 95-104.

Sowislo, J. F. \& Orth, U. (2013). Does low self-esteem predict depression and anxiety? A metaanalysis of longitudinal studies. Psychological Bulletin, 139, 213-240.

Strauman, T. J. (2002). Self-regulation and depression. Self and Identity, 1, 151-157.

Uliaszek, A. A., Zinbar, R. E., Mineka, S., Craske, M. G., Griffith, J. W., Sutton, J. M., Epstein, A., \& Hammen, C. (2012). A longitudinal examination of stress generation in depressive and anxiety disorders. Journal of Abnormal Psychology, 121, 4-15. 
Vandenberg, R. J. \& Lance, C. E. (2000). A review and synthesis of the measurement invariance literature: Suggestions, practices, and recommendations for organizational research. Organizational Research Methods, 3, 4-70.

Verboom, C. E., Sijtsema, J. J., Verhulst, F. C., Penninx, B. W. J. H., \& Ormel, J. (2014). Longitudinal associations between depressive problems, academic performance, and social functioning in adolescent boys and girls. Developmental Psychology, 50, 247-257.

Watson, D. (2005). Rethinking the mood and anxiety disorders: A quantitative hierarchical model for DSM-V. Journal of Abnormal Psychology, 114, 522-536.

Watson, D. \& Pennebaker, J. W. (1989). Health complaints, stress, and disease: Exploring the central role of negative affectivity. Psychological Review, 96, 234-254.

Wigfield, A., Eccles, J. S., MacIver, D., Reuman, D. A. \& Midgley, C. (1991). Transitions during early asolescence: Changes in children's domain-specific self-perceptions and general self-esteem across the transition to junior high school. Developmental Psychology, 27, 552-565.

Zimmerman, M. A., Caldwell, C. H., \& Bernat, D. H. (2002). Discrepancy between self-report and school-report grade point average: Correlates with psychosocial outcomes among African American adolescents. Journal of Applied Social Psychology, 32, 86-109. 


\section{Footnotes}

1 In this paper, we use the term internalizing symptomatology to refer to depression and anxiety, in light of substantial evidence suggesting that major depression, dysphoria, and generalized anxiety disorder constitute a common class of psychiatric disorders labeled anxiousmisery, distress disorders, or internalizing disorders (Kendler, Prescott, Myers, \& Neale, 2003; Krueger, 1999; Watson, 2005).

2 In line with prior work indicating that depressive symptoms tend to increase linearly during adolescence (e.g., Kuoros \& Garber, 2014), we included a linear slope term for depression and anxiety in the bivariate ALTMs. However, to directly test whether a linear or quadratic trend best characterized the data, we fit bivariate Latent Growth Curve (LGC) models for depression and anxiety (i.e., one model with depression and GPA, one model with anxiety and GPA), which included both a linear and quadratic slope. These preliminary analyses indicated that models including a quadratic slope for depression and anxiety did not fit the data well, and we therefore proceeded with a linear slope term.

3 Participants' high school grade point average, taken from final grade reports generated upon graduation, was also collected. We ran bivariate ALTMs in which high school GPA was allowed to correlate with intercept and slope terms for both depression and anxiety; high school GPA showed no statistically significant $(p s>.05)$ relations with intercepts or slopes, and will not be discussed further.

4 Grade 6 negative and positive affect were not included as covariates, because grade 6 depression and anxiety were treated as predetermined.

5 In additional ancillary analyses we also sought to examine whether the relations between internalizing symptomatology and academic achievement held when controlling for IQ and 
gender. IQ was measured via the reading, spelling, and math subscales of the Wechsler Individual Achievement Test, in grades 6 to 9. Specifically, we used IQ and gender as covariates in separate models for both depression and anxiety, by regressing internalizing symptomatology and academic achievement in each year on IQ in the corresponding year, or by regressing each internalizing symptomatology and academic achievement assessment on gender. These models showed reasonable fit for IQ (Depression: $\chi^{2}(25)=63.11, p<.001, \mathrm{CFI}=.96, \mathrm{TLI}=.91$; RMSEA $=.11 ;$ anxiety: $\left.\chi^{2}(25)=71.30, p<.001, \mathrm{CFI}=.95, \mathrm{TLI}=.91 ; \mathrm{RMSEA}=.12\right)$ and excellent fit for gender (Depression: $\chi^{2}(25)=31.29, p=.18$, CFI $=1.00$, TLI $=.99$; RMSEA $=.04$; anxiety: $\left.\chi^{2}(25)=29.02, p=.26, \mathrm{CFI}=1.00, \mathrm{TLI}=.99 ; \mathrm{RMSEA}=.04\right)$. Most importantly, the pattern of bi-directional prospective effects again remained relatively unchanged, compared to the results of our primary models. In both the models including IQ and gender, depression ( $b \mathrm{~s}$ $=-.19$ to -.85$)$ and anxiety $(b s=-.30$ to -.96$)$ continued to exert negative effects on subsequentyear GPA, and GPA continued to exert a negative, effect on same-year internalizing symptomatology (depression: $b \mathrm{~s}=-.12$ to -.14 ; anxiety: $b \mathrm{~s}=-.12$ to -.19 ). 
Table 1 Model Fit Indices

\begin{tabular}{|c|c|c|c|c|c|c|c|c|}
\hline Model & Constraint & $\chi^{2}$ & $d f$ & $p$-value & CFI & TLI & RMSEA & AIC \\
\hline \multicolumn{9}{|l|}{ Depression } \\
\hline ARM & -- & 75.80 & 28 & $<.001$ & .96 & .93 & .12 & 523.38 \\
\hline BALTM & -- & 35.78 & 22 & .03 & .99 & .98 & .07 & 487.69 \\
\hline BALTM & Equal GPA to Depression Cross-Lags & 37.60 & 25 & .05 & .99 & .98 & .06 & 483.51 \\
\hline BALTM & Equal Depression to GPA Cross-Lags & 59.66 & 25 & $<.001$ & .97 & .95 & .10 & 505.57 \\
\hline \multicolumn{9}{|l|}{ Anxiety } \\
\hline ARM & -- & 77.54 & 28 & $<.001$ & .96 & .96 & .12 & 304.12 \\
\hline BALTM & -- & 30.01 & 22 & .12 & .99 & .99 & .05 & 257.34 \\
\hline BALTM & Equal GPA to Anxiety Cross-Lags & 34.79 & 25 & .09 & .99 & .99 & .06 & 256.12 \\
\hline BALTM & Equal Anxiety to GPA Cross-Lags & 51.50 & 25 & $<.001$ & .98 & .96 & .09 & 272.83 \\
\hline
\end{tabular}

Notes. ARM: autoregressive model; BALTM: bivariate autoregressive latent trajectory model

$\mathrm{GPA}=$ grade point average 
Table 2 Parameter Estimates for BALT Models

\begin{tabular}{|c|c|c|c|c|c|c|c|c|}
\hline Internalizing Variable & Depression & Anxiety & PA & NA & Depression & Anxiety & Depression & Depression \\
\hline Covariate & -- & -- & -- & -- & $\mathrm{NA}$ & NA & $\mathrm{PA}$ & PA \\
\hline $\mathrm{I}_{\mathrm{I}}-\mathrm{I}_{\mathrm{G}}$ & .05 & .08 & -.16 & .01 & .01 & .03 & -.02 & .02 \\
\hline $\mathrm{S}_{\mathrm{I}}-\mathrm{S}_{\mathrm{G}}$ & .00 & .00 & .00 & -.01 & .00 & .00 & .00 & .00 \\
\hline $\mathrm{I}_{\mathrm{I}^{-}} \mathrm{S}_{\mathrm{I}}$ & -.01 & .00 & $-.09 *$ & -.02 & .00 & .00 & .00 & .00 \\
\hline $\mathrm{I}_{\mathrm{G}^{-}} \mathrm{S}_{\mathrm{G}}$ & $-.07 *$ & $-.07 *$ & $-.07 *$ & $-.07 *$ & $-.07 *$ & $-.07 *$ & $-.06 *$ & $-.06 *$ \\
\hline $\mathrm{I}_{\mathrm{I}}-\mathrm{S}_{\mathrm{G}}$ & .00 & .00 & -.02 & .02 & .00 & .01 & .00 & .00 \\
\hline $\mathrm{I}_{\mathrm{G}}-\mathrm{S}_{\mathrm{I}}$ & .00 & .00 & .04 & .01 & .00 & .00 & .01 & .01 \\
\hline $\mathrm{I}_{\mathrm{y} 7^{-}}>\mathrm{G}_{\mathrm{y} 7}$ & $-.48 *$ & $-.55 \dagger$ & -.04 & -.04 & -.20 & -.19 & -.35 & -.38 \\
\hline $\mathrm{I}_{\mathrm{y} 8}->\mathrm{G}_{\mathrm{y} 8}$ & -.13 & -.21 & .00 & .02 & $-.28 \dagger$ & $-.32 \dagger$ & $-.26 \dagger$ & -.24 \\
\hline $\mathrm{I}_{\mathrm{y} 9^{-}}>\mathrm{G}_{\mathrm{y} 9}$ & $-.29 \dagger$ & $-.47 *$ & -.01 & -.04 & -.19 & -.35 & $-.44 *$ & $-.40 \dagger$ \\
\hline $\mathrm{I}_{\mathrm{y} 10^{-}}>\mathrm{G}_{\mathrm{y} 10}$ & $-.66 *$ & $-.75 *$ & -.01 & -.11 & $-.59 \dagger$ & -.43 & $-.89 *$ & $-.64 *$ \\
\hline $\mathrm{G}_{\mathrm{y} 6}->\mathrm{I}_{\mathrm{y} 7}$ & $-.14 *$ & $-.14 *$ & .18 & -.19 & -.08 & $-.06 *$ & $-.08 \dagger$ & $-.09 *$ \\
\hline $\mathrm{G}_{\mathrm{y} 7}->\mathrm{I}_{\mathrm{y} 8}$ & $-.14 *$ & $-.14 *$ & .18 & -.19 & -.08 & $-.06 *$ & $-.08 \dagger$ & $-.09 *$ \\
\hline $\mathrm{G}_{\mathrm{y} 8}->\mathrm{I}_{\mathrm{y} 9}$ & $-.14 *$ & $-.14 *$ & .18 & -.19 & -.08 & $-.06 *$ & $-.08 \dagger$ & $-.09 *$ \\
\hline $\mathrm{G}_{\mathrm{y} 9-}>\mathrm{I}_{\mathrm{y} 10}$ & $-.14 *$ & $-.14 *$ & .18 & -.19 & -.08 & $-.06 *$ & $-.08 \dagger$ & $-.09 *$ \\
\hline
\end{tabular}

Notes. "—“": correlation between two latent variables; "->” unstandardized regression coefficient; * $p<.05$, $\uparrow p<.10$; BALTM:

bivariate autoregressive latent trajectory model; I = internalizing symptomatology or positive/negative affect; G = GPA; PA = positive affect; NA = negative affect; $\mathrm{I}=$ intercept; $\mathrm{S}=$ slope; $\mathrm{y}=$ year; Path coefficients are unstandardized. 


\section{Figure Captions}

Figure 1: Primary bivariate ALTM used to model relationships between internalizing symptomatology and GPA. Squares represent observed variables, circles represent latent variables. Single-headed arrows represent one-way path coefficients, double-headed arrows represent covariances. To simplify visual representation, paths representing covariances between internalizing intercept/GPA slope and GPA intercept/internalizing slope are not displayed, nor are residual disturbances for endogenous variables. Internalizing = either depression or anxiety; $G P A=$ grade point average 
Figure 1

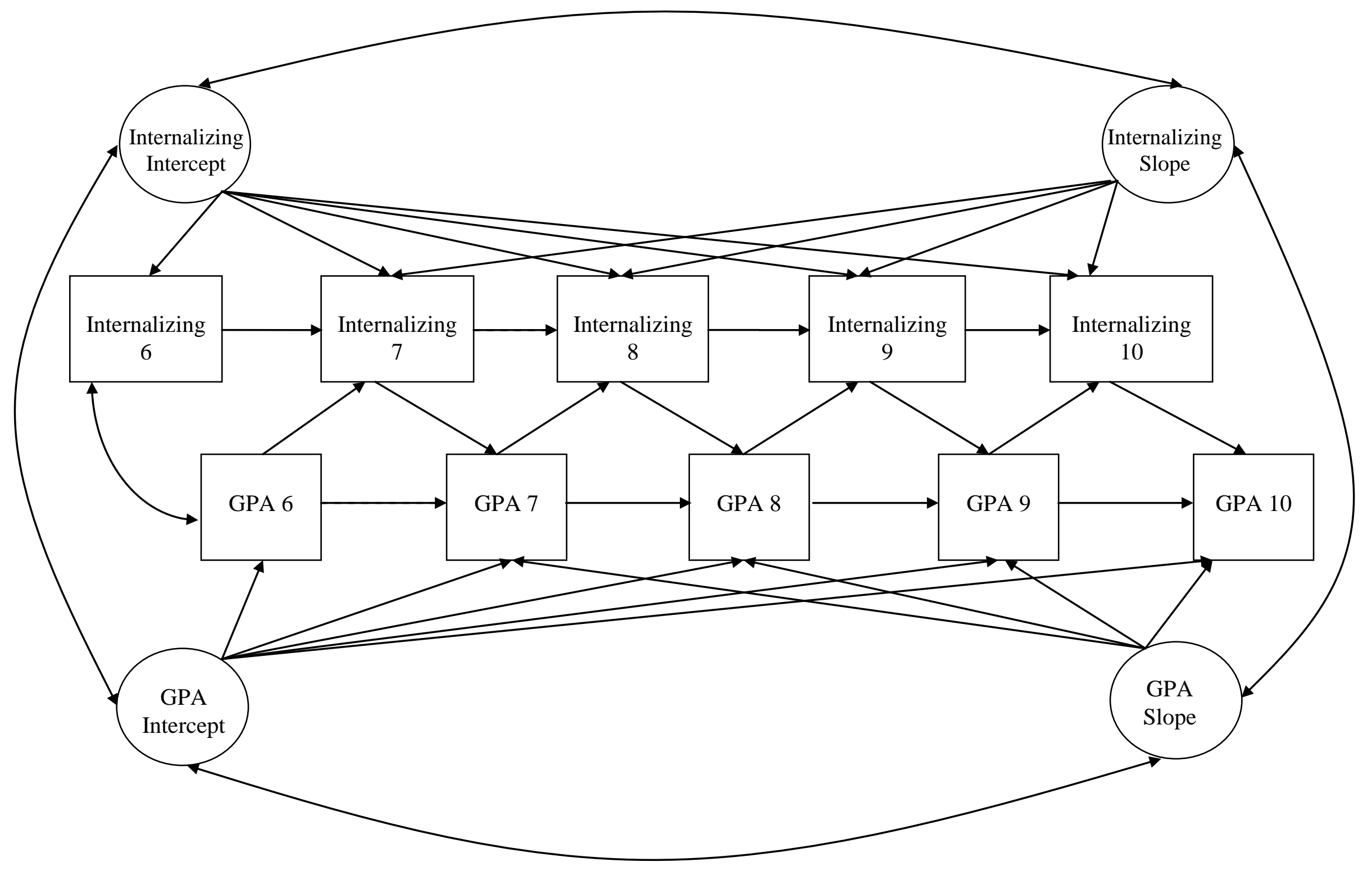

